\title{
Transcriptional and translational modulation of KAI1 expression in ductal carcinoma of the breast and the prognostic significance
}

\author{
FRAZ A. MALIK ${ }^{1,3}$, ANDREW J. SANDERS ${ }^{1}$, ANTHONY DOUGLAS JONES ${ }^{2}$, \\ ROBERT E. MANSEL ${ }^{1}$ and WEN G. JIANG ${ }^{1}$ \\ ${ }^{1}$ University Departments of Surgery and ${ }^{2}$ Pathology, Cardiff University School of Medicine, Cardiff, Wales, UK
}

Received September 11,2008; Accepted October 27, 2008

DOI: 10.3892/ijmm_00000127

\begin{abstract}
KAI1, also known as CD82, has been shown to have a potential impact on the invasiveness of cancer cells. In the present study, expression pattern of KAI1, both at transcription and translation levels and the potential clinical value of the expression were explored in a cohort of normal and ductal mammary cancer tissues $(n=71)$. A marked reduction of KAI1 transcript was observed in invasive ductal breast tumours as compared to normal tissues. Expression of KAI1 protein was higher in normal tissues as compared to tumour samples. Though no significant difference of KAI1 expression between different grades of tumour was observed $(\mathrm{p}=0.064)$, significant correlation of TNM staging with KAI1 expression has been observed in invasive ductal breast cancer patients $(\mathrm{p}=0.045)$. Additionally, it was also observed that patients showing higher expression of KAI1 had a longer 10 -year survival rate as compared to a low level or completely negative expression KAI1 ( $\mathrm{p}=0.0136)$. KAI1 inverse correlation with tumour progression may be used as a strong prognostic marker.
\end{abstract}

\section{Introduction}

Breast cancer is one of the most frequently occurring cancers amongst females across the globe. According to the American Cancer Association, women of all origin have a substantial risk of developing breast cancer (incidence rate in Caucasians

Correspondence to: Dr Wen G. Jiang, Department of Surgery, Cardiff University School of Medicine, Cardiff, Wales CF14 4XN, UK

E-mail: jiangw@cardiff.ac.uk

Present address: ${ }^{3}$ Cancer Genetics Lab, Department of Biosciences, COMSATS Institute of Information Technology, Islamabad, Pakistan

Abbreviations: MSGs, metastasis suppressor genes; IHC, immunohistochemistry; PCR, polymerase chain reaction

Key words: KAI1, CD82, ducal carcinoma, breast cancer, survival, metastasis
130.8; African Americans 111.5; Asian Americans and Pacific islanders 91.2; American Indians 74.4 per 100,000). Metastasis is the primary cause of death for the patients. Metastasis, a complex biological and clinical event, is influenced by a number of molecules. These molecules, by acting on the breast cancer cells and stromal cells, impact on the cellular behaviours of cancer cells during the metastatic process. KAI1 (Kang ai as from Chinese meaning anticancer) is one of these molecules and is a member of the tetraspanin family that was first identified in a T-cell activation study (1). Metastasis suppression induced by this gene in prostate cancer was explored later on by somatic cell hybridization of highly metastatic and non-metastatic rat prostate cancer cells (2). KAI1 is also termed as SAR2 leukocyte surface antigen R2 and suppressor of tumorigenicity 6 (ST6). Dong et al, identified the location of KAI1 gene on chromosome 11p with 10 exons and 9 introns spanning $\sim 80 \mathrm{~kb}$ (3). KAI1 protein exists in two isoforms, with 267 residues in isoform-1 and 242 residues in isoform-2 (4). KAI1 plays an important role in cancer largely due to its interesting relationship with other molecules that are strongly linked to the function of cancer cells.

It has been established in recent years that apart from interacting with other members of the tetraspanin family, KAI1 protein molecule interacts with integrins and epidermal growth factor receptor (EGFR) $(5,6)$, in doing so KAI1 aids the internalisation of integrins and EGFR. This may result in loss of reduction of integrins and EGFR, pivotal regulators of cell adhesion and growth in breast cancer. Altered expression of KAI1 ultimately leads to decrease in adhesion and increase invasiveness of cancer cells. KAI1 has an ectopic effect on adhesion by strengthening the interaction among E-cadherin with B-catenins and reduces the chances of cellular dissemination for the primary tumour (7).

Expressional regulation of these genes in relation to various clinical parameters during cancer progression have been reported in prostate cancer $(8)$, breast $(9,10)$, lung $(11)$, ovarian (12), gastric $(13,14)$, pancreatic $(15)$, oesophagus $(16)$, bladder (17) and cervical cancer (18). Inverse correlation of KAI1 expression with respect to cancer progression has been observed in all these studies. It has been observed that a decreased expression of KAI1 is associated with poor prognosis. The aim of the present study was not only to screen 
Table I. Clinical pathological features of the cohort of the ductal carcinoma of the breast.

\begin{tabular}{|c|c|c|c|c|}
\hline \multirow{2}{*}{$\begin{array}{l}\text { Groupings } \\
\text { Grade }\end{array}$} & \multicolumn{4}{|c|}{ Number of samples } \\
\hline & & $\begin{array}{c}\text { Grade-1 } \\
n=9\end{array}$ & $\begin{array}{c}\text { Grade- } 2 \\
n=24\end{array}$ & $\begin{array}{c}\text { Grade-3 } \\
n=38\end{array}$ \\
\hline TNM staging & & $\begin{array}{c}\text { TNM1 } \\
\text { n=38 }\end{array}$ & $\begin{array}{c}\text { TNM2 } \\
\mathrm{n}=27\end{array}$ & $\begin{array}{c}\text { TNM3/4 } \\
n=6\end{array}$ \\
\hline NPI status & & $\begin{array}{c}\text { NPI }<3.4 \\
n=35\end{array}$ & $\begin{array}{c}\text { NPI } 3.4-5.4 \\
n=27\end{array}$ & $\begin{array}{c}\text { NPI }>5.4 \\
n=9\end{array}$ \\
\hline Clinical outcome & $\begin{array}{l}\text { Disease-free } \\
\quad \mathrm{N}=52\end{array}$ & $\begin{array}{l}\text { With metastasis } \\
\qquad \mathrm{N}=7\end{array}$ & $\begin{array}{l}\text { With local recurrence } \\
\qquad \mathrm{N}=4\end{array}$ & $\begin{array}{l}\text { Died of breast cancer } \\
\qquad \mathrm{N}=8\end{array}$ \\
\hline
\end{tabular}

expression levels of KAI1 molecule in breast cancer patients but also to find a correlation (if any) with the tumour stage, as well as long-term survival of the patients.

\section{Materials and methods}

RNA-extraction kits and Mastermix for routine PCR and quantitative PCR were obtained from AbGene (Surrey, UK). PCR primers were designed using Beacon designer (Palo Alto, CA, USA) and synthesised by Invitrogen (Paisley, UK). Molecular biology grade agarose and DNA ladder were purchased from Invitrogen.

The first strand cDNA synthesis kit was purchased from Sigma Chemical Ltd. (Dorset, UK). A universal IHC kit was purchased from Vector Laboratories (Peterborough, UK). Low fluorescent 96-well plates were obtained from AbGene and sealing film was purchased from BioRad (Hemel Hempstead, UK).

Breast sample collection. Ductal breast cancer tissues $(n=71)$ and normal tissues $(n=31)$ that were free from cancer cells were collected (with approval from the local ethics committee) immediately after surgery and stored at $-80^{\circ} \mathrm{C}$ until required. These patients were routinely followed clinically after surgery. Median follow-up was 120 months. Histopathological features, tumour grade, tumour staging and the prognostic index for the patients are shown in Table I.

Tissue processing. Frozen sections of breast tissues were cut using cryostat at a thickness of 5-10 $\mu \mathrm{m}$ and were stored at $-20^{\circ} \mathrm{C}(19,20)$. Approximately $15-20$ sections from each breast tissue sample were homogenized using a hand held homogenizer in ice-cold RNA extraction buffer. Concentration of RNA was confirmed by using UV spectrophotometer (Wolf Laboratories, York, UK).

cDNA synthesis and analysis of the KAIl transcript. Reverse transcription was carried out by using $1 \mu \mathrm{g}$ of total RNA from each sample. Oligo-dT primer present in the RT kit was used and cDNA was prepared according to the manufacturer's instructions. Polymerase chain reaction was preformed using this synthesized cDNA. Reaction conditions were $95^{\circ} \mathrm{C}$ for $5 \mathrm{~min} ; 94^{\circ} \mathrm{C}$ for $20 \mathrm{sec} ; 55^{\circ} \mathrm{C}$ for $30 \mathrm{sec}, 72^{\circ} \mathrm{C}$ for $1 \mathrm{~min}$ for 38 cycles with $10 \mathrm{~min}$ final extension at $72^{\circ} \mathrm{C}$. The following primers were used in the reaction, KAI1 forward: 5'CTGTACTTTGCTTTCCTGCT'3 and KAI1 reverse: 5'CTGTAGTCTTCGGAATGGAC'3. ß-actin was used as internal control in the experiment. Amplified products were visualized, following staining with $2 \%$ agarose gel.

Quantitative PCR analysis. Transcripts of all patients were analysed by using IQ real-time quantitative Thermal cycler (BioRad). Specific pairs of primers were designed using Beacon Designer and synthesized by Invitrogen. Sense primers for KAI1 (5'CATTCGAGACTACAACAGCA3') and antisense primer including $\mathrm{Z}$ sequence (complementary to universal probe 5'ACTGAACCTGACCGTACATCCAGTTGTAGA AGCTGACC'3) were used for its detection. GAPDH was used as an internal control in this quantitative reaction (primer pair for GAPDH: 5'CTGAGTACGTCGTGGAGTC'3 and 5'ACT GAACCTGACCGTACACAGAGATGATGACCCTTTTG'3). The reaction was carried out using the following reaction conditions: Hot-start Q-master mix (Abgene), 10 pmol of specific forward primer, 1 pmol of antisense primer (containing $\mathrm{Z}$ sequence). A probe of 100 pmol concentration of (6 carboxy-fluorescein FAM) was used. The reaction conditions were $94^{\circ} \mathrm{C}$ for $120 \mathrm{~min} ; 94^{\circ} \mathrm{C}$ for $150 \mathrm{sec}$, $55^{\circ} \mathrm{C}$ for $400 \mathrm{sec}$ and $72^{\circ} \mathrm{C}$ for $200 \mathrm{sec}$ with 60 cycles. The data generated was first normalized with the GAPDH molecule.

Immunohistochemical staining. Immunohistochemical staining was done using both tumour and normal frozen sections of $6 \mu \mathrm{m}$ thickness. The sections were mounted on Super Frost Plus microscopic slides and air dried for 20-30 min. These fixed tissue sections were treated in $50 \%$ methanol and $50 \%$ acetone for $15 \mathrm{~min}$. Sections were then air dried for $10 \mathrm{~min}$ and stored at $-20^{\circ} \mathrm{C}$ (wrapped in foil) for further use or immediately stained. These air dried samples were placed in PBS for 5 min to rehydrate, followed by blocking using a buffer with $10 \%$ horse serum. These sections were then treated with primary antibodies. Antibodies used for KAI1 were purchased from Santa Cruz Biotechnologies (Santa Cruz, CA) raised in rabbit. After a 1-h incubation of primary antibodies 

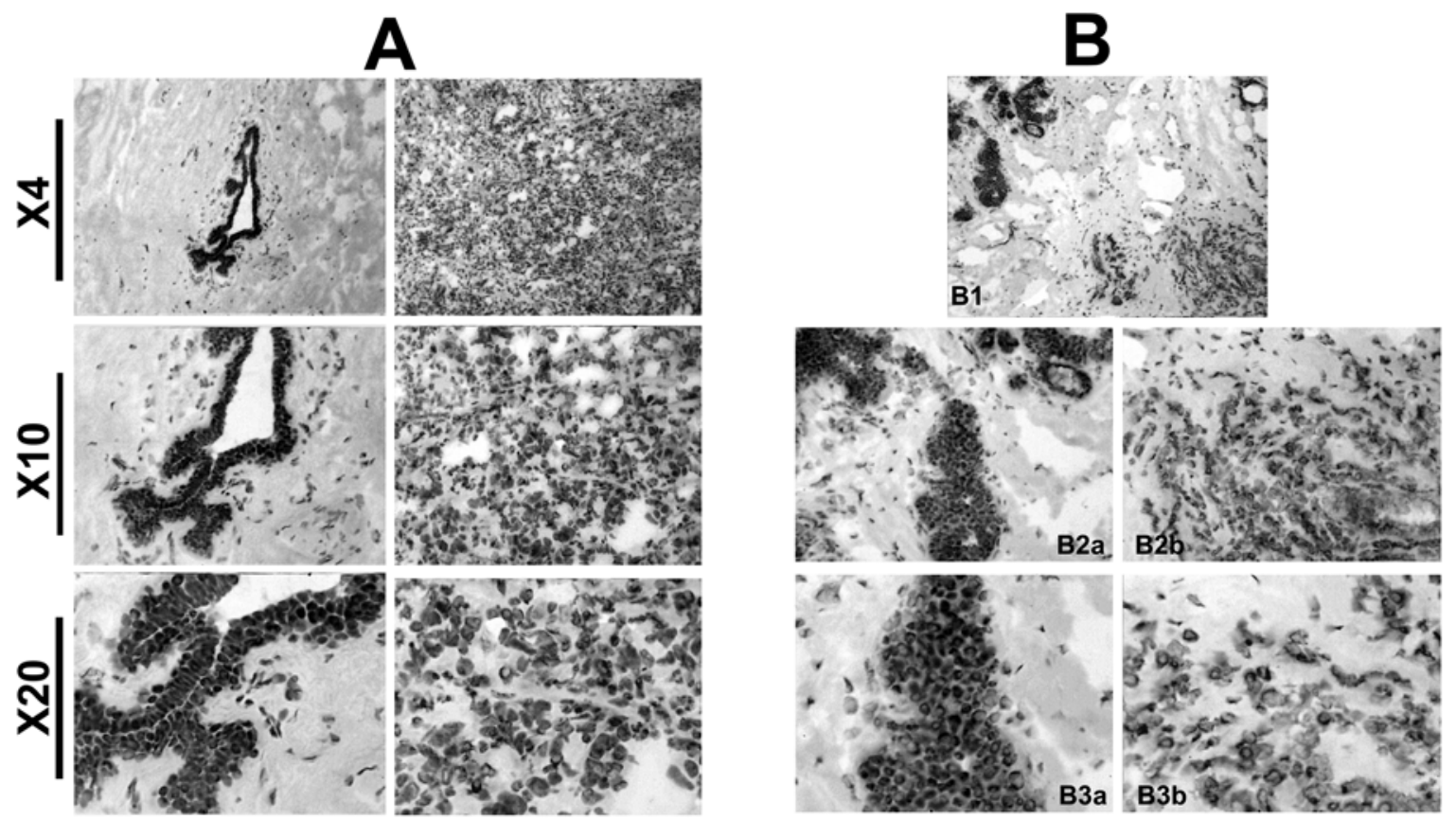

Figure 1. Immunohistochemical staining of KAI1 in frozen sections of unaffected normal mammary tissues and tumour tissues. (A) Comparison between unaffected normal tissues (left panel, ID 136) and an invasive tumour (ID 111). (B) Comparison between residual mammary cells (B2a and B3a) and invasive tumour cells (B2b and B3b) in the same sample (ID 113). Tumour cells showed a marked reduction of KAI1 staining compared with affected mammary epithelial cells.

the slides were subjected to 4 washes with PBS and then treated in universal multi-link biotinylated secondary antibody. After 30 min of incubation, 4 washes with PBS were performed on these slides. Slides were then treated with avidin biotin complex (ABC, Vector Labs, UK). Diaminobenzidine tetrahydrochloride [3,3-diaminobenzidine (DAB) purchased from Sigma] was added for 5 min to detect the bound antibody. The slides were washed with water for $5 \mathrm{~min}$ and treated with Mayer's haematoxylin for 1 min followed by a further wash with water for $10 \mathrm{~min}$. The slides were then treated with methanol ( 3 times) and clearing in 2 changes of xyline before mounting under a cover slip. PBS is used as negative control in this experiment. Each experiment was repeated thrice for conclusive results.

Statistical analysis was carried out using Mann-Whitney U test (IQR) and survival analysis by Kaplan Meier survival analysis, using SPSS package (SPSS version 16).

\section{Results}

Distribution of KAII in mammary cells. After immunohistochemical staining, the presence of KAI1 protein was confirmed in breast tissue. KAI1 was observed in tumour cells as well as in normal cells. The protein was localized on the cell membrane and in the cytosol. Dark brown staining was observed on the cell boundaries of normal cells indicating the presence of KAI1. KAI1 protein was more abundantly observed in mammary epithelial cells in unaffected tissues (Fig. 1A left panel and B2a) as compared to cancer cells (Fig. 1A right panel and $\mathrm{B} 2 \mathrm{~b}$ ).

Expression of the KAII transcripts in breast cancer cells and tissues. Conventional RT-PCR highlights alteration in KAI-1
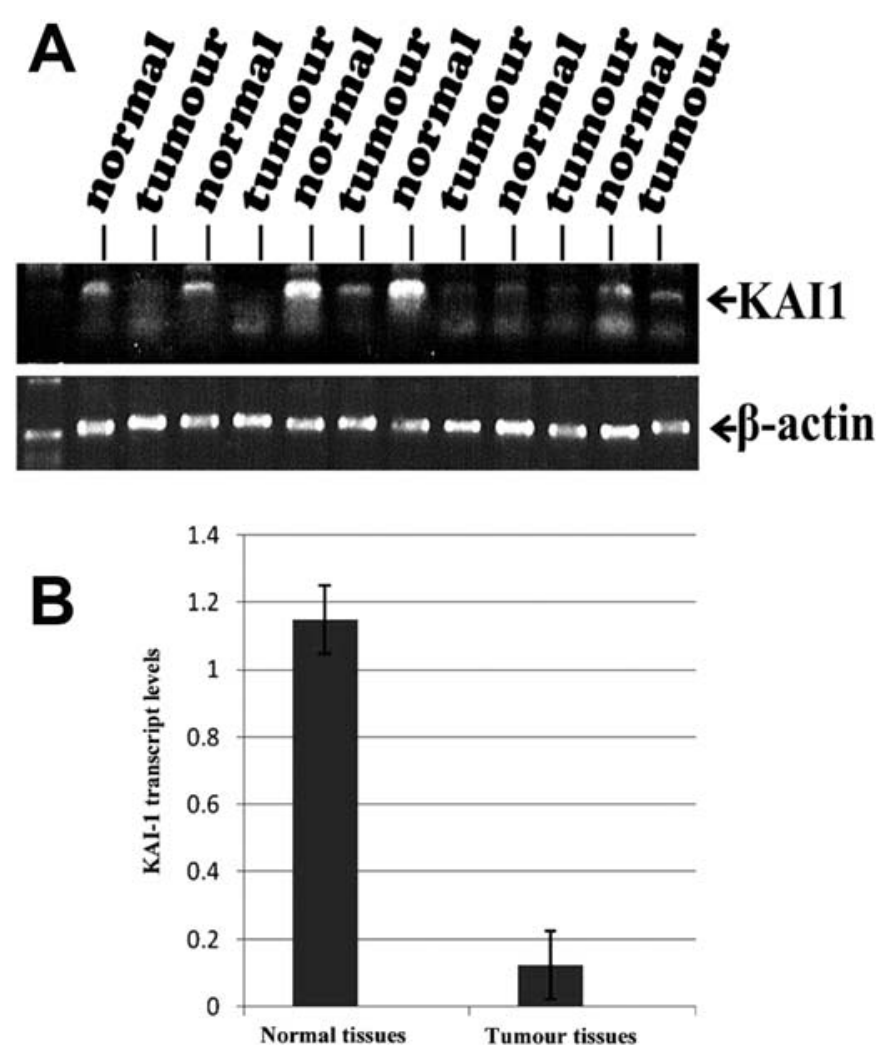

Figure 2. Expression of KAI1 transcripts in human mammary tissues. (A) Expression pattern of KAI1 transcript by using conventional RT-PCR (shown are PCR products separated by $2 \%$ agarose gel electrophoresis). Almost complete loss of KAI1 mRNA is clearly evident in ductal breast tumour samples in comparison to $B$-actin which was used as internal control. (B) KAI1 expression levels in normal and ductal breast tissue in the cohort by quantitative real-time PCR analysis (shown are medians of KAI1/ GAPDH ratios). Ductal breast tissue samples showed a significant decrease of KAI1 transcript in comparsion to normal tissue samples. 
Table II. Summary of KAI-1 transcript levels in the study cohort. ${ }^{\mathrm{a}}$

\begin{tabular}{|c|c|c|}
\hline Group & KAI1 transcript (median and IQR) & p-value (Mann-Whitney U test) \\
\hline \multicolumn{3}{|l|}{ Grade } \\
\hline 1 & 0.0045 (IQR 0.003-0.0353) & \\
\hline 2 & 0.002 (IQR 0-0.005) & NS \\
\hline 3 & 0.003 (IQR 0-0.033) & NS \\
\hline \multicolumn{3}{|l|}{ NPI index } \\
\hline$<3.4$ & 0.002 (IQR 0-0.025 ) & \\
\hline $3.4-5.4$ & 0.003 (IQR 0-0.016) & NS \\
\hline$>5.4$ & 0.041 (IQR 0.001-0.0335) & NS \\
\hline \multicolumn{3}{|l|}{ Clinical outcome } \\
\hline Disease free & 0.004 (IQR 0.001-0.029) & \\
\hline With metastasis & $0.02($ IQR $0-0.04)$ & NS \\
\hline With local recurrence & 0.021 (IQR 0.006-.041) & NS \\
\hline Died of breast cancer & $<0.0001$ (IQR 0-0.0008) & $\mathrm{p}=0.0136$ vs. disease-free \\
\hline
\end{tabular}

aShown are median levels and interquartile range (IQR) of KAI1/GAPDH ratio in the respective group. NPI, Nottingham Prognostic Index; NS, not significant.

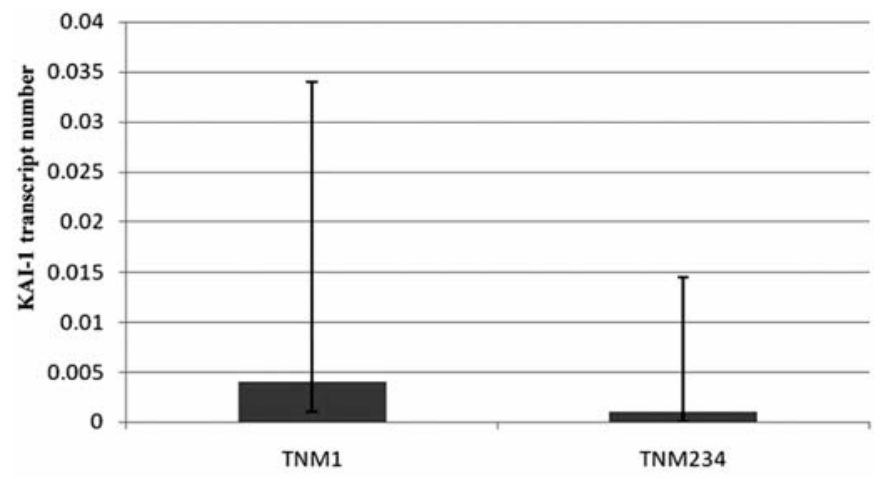

Figure 3. Correlation of KAI1 transcripts with tumour staging of ductal breast cancer. Significant correlation of KAI1 transcript number normalized to glyceraldehyde 3-phosphate dehydrogenase (GAPDH) against tumour, node and metastasis (TNM) staging were observed $(\mathrm{p}=0.0455)$. Shown are median and interquartile range (IQR) of KAI1/GAPDH ratio in the respective group.

expressional levels between paired normal and tumour tissues. In majority of these paired samples KAI1 levels appear to be reduced in the tumour tissue as compared to normal samples as shown in Fig. 2A. Further verification was done through quantitative real-time PCR that showed a decrease of KAI1 expression in all breast cancer samples as shown in Fig. 2B. The data presented are after normalizing with GAPDH.

Correlation of KAII transcripts with nodal status, grade and tumour staging. We were unable to identify any significant correlation of KAI1 transcript level between grade 1 (welldifferentiated), grade 2 (moderately differentiated) and grade 3 (poorly differentiated) of invasive ductal breast cancer tissues. No significant correlation with NPI (Nottingham Prognostic Index) has been observed (Table II). Early stage breast tumours (TNM1) had a significantly highly levels of KAI1 transcripts compared with late stage tumours (TNM2, 3 and 4) $(\mathrm{p}=0.045$, Fig. 3).
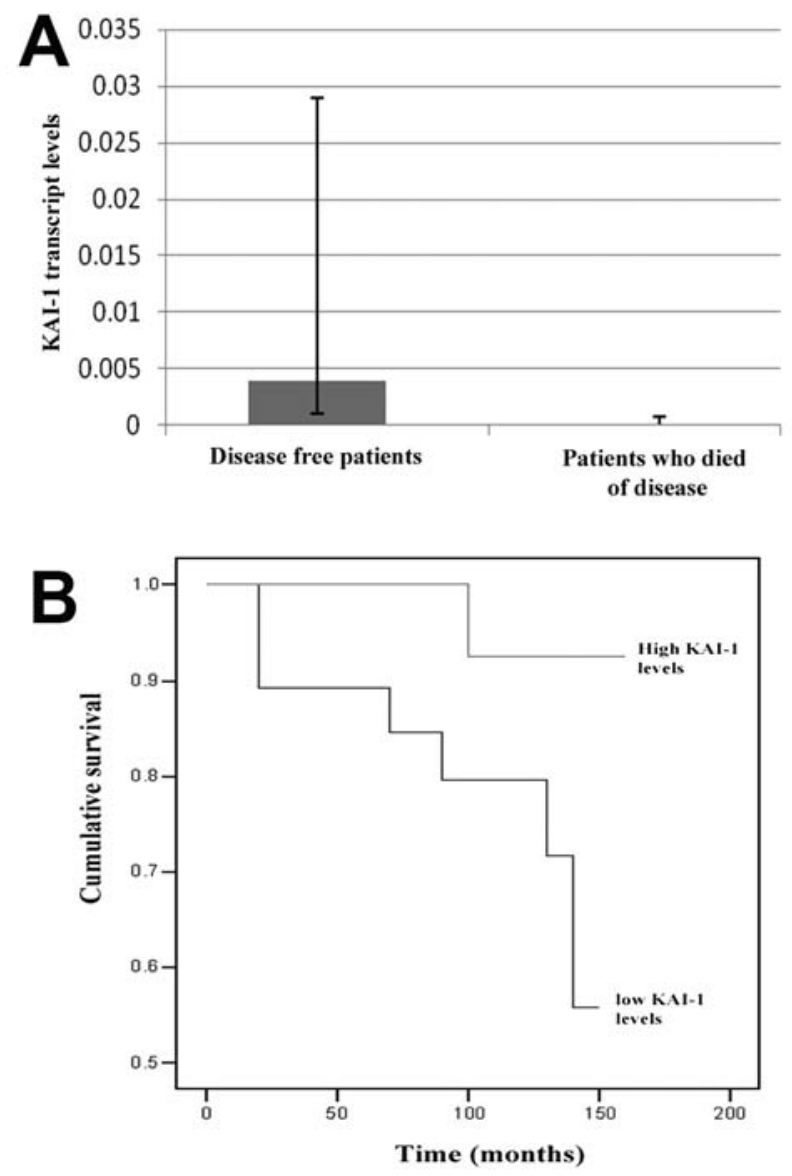

Figure 4. KAI1 transcript levels in ducal carcinoma linked to long-term survival of the patients. (A) Graphical illustration of survival rate in patients with KAI1 expression. Increase survival of breast cancer patients were observed in patients showing strong KAI1 expression in comparison to KAI1 negative patients. Shown are median and interquartile range (IQR) of KAI1/GAPDH ratio in the respective group. (B) Kaplan-Meier survival curve after 10 years of follow-up. Significant association of KAI1 level $(\mathrm{p}=0.0136)$ based on KAI1/glyceraldehyde 3 phosphate dehydrogenase (GAPDH) ratio indicating survival of patients with ductal carcinoma had been observed. 
Impact on patients survival. Patients who were disease-free had a significantly higher levels of KAI1 transcripts than those who died of breast cancer ( $\mathrm{p}=0.0136$, Fig. $4 \mathrm{~A})$. Using the Kaplan-Meier survival model, we found that patients with high levels of KAI1 transcripts had a significantly longer survival [mean survival 152 (95\% confident interval 144-160 months)] than patients with low level of KAI1 [120 (95\%CI 104-137) months)] ( $\mathrm{p}=0.0136$ ) (Fig. 4B).

\section{Discussion}

Metastasis suppression character of KAI1 was first discovered in prostate cancer which was later extrapolated in other types of cancer. The most significant findings of the present study are the correlation with KAI1 transcript and patients longterm survival. After 10 years of follow-up it was observed that patients showed a direct correlation between expression of KAI1 and survival. Disease-free survival rate was significantly higher in patients showing higher levels of KAI1 at the initial stage of mammary tumours compared to those who died as a result of cancer. This relationship of KAI1 expression with patients survival rate was also mentioned ( $\mathrm{p}=0.0091$ in 62 patients) in an earlier study (21). Similarly in another study, the 5-year disease-free survival rate of KAI1 positive tumour patients was more than KAI1 negative tumour patients $(p=0.0292)$ (9). Disease-free survival rate of KAI1 positive tissue has also been observed in relation to other types of cancers such as epithelial ovarian carcinoma (22), lung cancer (11), pancreatic cancer (15) and gastric cancer (12). As overall survival rates of lung cancer patients was significantly better in patients showing increased expression of KAI1 compared to patients showing a decrease in KAI1 as observed by Adachi et al (23). Similarly decreased level of KAI1 protein in advance stage gastric cancer patients also increase cancer-related death (12) providing a strong evidential usage of KAI1 along with other markers as a potential prognostic marker.

Decreased expression of KAI1 was consistently reported in breast cancer progression $(9,10,22,24)$ but significant correlation with respect to clinical progression of breast cancer stages was lacking. In a study on a Korean population Son et al showed a consistent decrease of KAI1 in infiltrating ductal carcinoma of breast but did not find any significant correlation with clinicopathological features (21). In the present study, a correlation of KAI1 with tumour node and metastasis system was identified which may later along with other markers be used as a better prognostic marker. These findings are also in accordance with a previous study on lung cancer (25) indicating a significant relationship with differentiated degree of tumour TNM stages and lymph node metastasis.

Down-regulation of KAI1 is attributed more toward expressional regulation rather than the involvement of coding region mutations. As mentioned also in previous studies the chance of somatic as well as germline mutations on coding region of KAI1 molecule is an extremely rare event $(22,26,27)$. KAI1 molecule has a transmembrane localization forming several interactions with integrin (28), chemokines (29), EGFR (30) and other tetraspanin (31). Suppression of cancer cells is actually induced by internalization of EGFR and also by accelerating desensitization of EGF signalling
(5). These interactions are responsible for cell-cell interaction, cell motility, and adhesion cell signalling. Increased KAI1 level both at transcript and translational scale actually reduce invasion of the breast cancer cells as mentioned in several previous reports (32-34). Thus, downregulations of KAI1 both at transcript as well as translation level in clinical cases ultimately lead to poor prognosis.

In conclusion, the association of KAI1 expression with breast cancer progression is a potential prognostic candidate marker. KAI1 metastatic suppression ability in conjunction with other markers can also be used as a marker of therapeutic potential. Apart from clinical trials, the role of KAI1 in various cellular signalling pathways is an area that requires further investigation.

\section{Acknowledgements}

We are extremely thankful to all those patients who provided their samples and time for this study. F.A.M. is a $\mathrm{PhD}$ student of COMSATs on a fellowship from Higher Education Commission of Pakistan. W.G.J. and A.J.S. thank Cancer Research Wales for supporting their work.

\section{References}

1. Gaugitsch HW, Hofer E, Huber NE, Schnabl E and Baumruker T: A new superfamily of lymphoid and melanoma cell proteins with extensive homology to Schistosoma mansoni antigen Sm23. Eur J Immunol 21: 377-383, 1991.

2. Ichikawa T, Ichikawa $Y$ and Isaacs JT: Genetic factors and suppression of metastatic ability of prostatic cancer. Cancer Res 51: 3788-3792, 1991

3. Dong JT, Lamb PW, Rinker-Schaeffer CW, Vukanovic J, Ichikawa T, Isaacs JT and Barrett JC: KAI1, a metastasis suppressor gene for prostate cancer on human chromosome 11p11.2. Science 268: 884-886, 1995.

4. Todeschini AR, Dos Santos JN, Handa K and Hakomori SI: Ganglioside GM2/GM3 complex affixed on silica nanospheres strongly inhibits cell motility through CD82/cMet-mediated pathway. Proc Natl Acad Sci 105: 1925-1930, 2008.

5. Nydegger S, Khurana S, Krementsov DN, Foti M and Thali M: Mapping of tetraspanin-enriched microdomains that can function as gateways for HIV-1. J Cell Biol 173: 795-807, 2006.

6. Odintsova E, Sugiura T and Berdeitchevski F: Attenuation of EGF receptor signalling by a metastasis suppressor, the tetraspanin CD82/KAI1. Curr Biol 10: 1009-1012, 2000.

7. Abe M, Sugiura T, Takahashi M, Ishii K, Shimoda M and Shirasuna K: A novel functions of CD82/KAI-1 on E-cadherinmediated homophilic cellular adhesion of cancer cells. Cancer Lett 266: 163-170, 2008.

8. Jackson P, Ow K, Yardley G, Delprado W, Quinn DI, Yang JL and Russell PJ: Down-regulation of KAI1mRNA in localized prostate cancer and its bony metastases do not correlate with p53 over expression. Prostate Cancer Prostatic Dis 6: 174-181, 2003.

9. Stark AM, Tongers K, Maass N, Mehdorn HM and Held-Feindt J: Reduced metastasis-suppressor gene mRNA-expression in breast cancer brain metastases. J Cancer Res Clin Oncol 131: 191-198, 2005.

10. Huang H, Groth J, Sossey-Alaoui K, Hawthorn L, Beall S and Geradts J: Aberrant expression of novel and previously described cell membrane markers in human breast cancer cell lines and tumours. Clin Cancer Res 11: 4357-4364, 2005.

11. Wang XY, Liu T, Zhu CZ, Li Y, Sun R, Sun CY and Wang AX: Expression of KAI1, MRP-1, and FAK proteins in lung cancer detected by high-density tissue microarray. Chin J Cancer 24: 1091-1095, 2005.

12. Houle CD, Ding XY, Foley JF, Afshari CA, Barrett JC and Davis BJ: Loss of expression and altered localization of KAI1 and CD9 protein are associated with epithelial ovarian cancer progression. Gynecol Oncol 86: 69-78, 2002. 
13. Tsutsumi S, Shimura T, Morinaga N, Mochiki E, Asao T and Kuwano H: Loss of KAI1 expression in gastric cancer. Hepatogastroenterology 52: 281-284, 2005.

14. Guan-Zhen Y, Ying C, Can-Rong N, Guo-Dong W, Jian-Xin Q and Jie-Jun W: Reduced protein expression of metastasis-related genes (nm23, KISS1, KAI1 and p53) in lymph node and liver metastases of gastric cancer. Int J Exp Pathol 88: 175-183, 2007.

15. Sho M, Adachi M, Taki T, Hashida H, Konishi T, Huang CL, Ikeda $\mathrm{N}$ and Miyake M: Transmembrane 4 superfamily as a prognostic factor in pancreatic cancer. Int J Cancer 79: 509-516, 1998 .

16. Farhadieh RD, Smee R, Ow K, Yang JL, Russell PJ, Crouch R, Jackson P and Jacobson IV: Down-regulation of KAI1/CD82 protein expression in oral cancer correlates with reduced disease free survival and overall patient survival. Cancer Lett 213: 91-98, 2004.

17. Jackson P, Rowe A and Grimm MO: An alternatively spliced KAI1 mRNA is expressed at low levels in human bladder cancers and bladder cancer cell lines and is not associated with invasive behaviour. Oncol Rep 18: 1357-1363, 2007.

18. Schindi M, Birner P, Bachtiary B, Breitenecker G, Selzer E and Oberhuber G: The impact of expression of the metastasis suppressor protein KAI1 on prognosis in invasive squamous cell cervical cancer. Anticancer Res 20: 4551-4555, 2000.

19. Jiang WG, Watkins G, Fodstad O, Douglas-Jones A, Mobel K and Mansel RE: Differential expression of the CCN family members Cyr61, CTGF and Nov in human breast cancer. Endocr Relat Cancer11: 781-791, 2003

20. Lane J, Mansel RE and Jiang WG: Delta-6-desaturase and FAD3 expression in human breast cancer. Int J Mol Med 12: 253-257, 2003

21. Son BH, Choi JS and Lee JH: Prognostic values of KAI1 and survivin expression in an infiltrating ductal carcinoma of the breast. Pathology 37: 131-136, 2005.

22. Liu FS, Dong JT, Chen JT, Hsieh YT, Ho ES and Hung MJ Frequent down-regulation and lack of mutation of the KAI1 metastasis suppressor gene in epithelial ovarian carcinoma. Gynecol Oncol 78: 10-15, 2000.

23. Adachi M, Taki T, Ieki Y, Huang C-L, Higashiyama M and Miyake M: Correlation of KAI1/CD82 gene expression with good prognosis in patients with non-small cell lung cancer. Cancer Res 56: 1751-1755, 1998.
24. Yang X, Wei L, Tang C, Slack R, Montgomery E and Lippman M: KAI1 protein is down-regulated during the progression of human breast cancer. Clin Cancer Res 6: 3424-3429, 2000.

25. Liu T, Wang X, Zhu C, Li Y, Sun C and Wang A: Expression of KAI1 protein in tissue microarray and its biological significances in patients with lung cancer. Chin J Lung Cancer 8: 116-119, 2005.

26. Malik FA, Kayani MA, Iqbal H, Jiang WG and Sadiq R: Characterization of coding region of metastasis suppressor genes KiSS1 and KAI-1 for germ line mutations in breast cancer patients. Gene Ther Mol Biol (In press).

27. Miyazaki T, Kato H, Shitara Y, Yoshikawa M, Tajima K, Masuda N, Shouji H, Tsukada K, Nakajima T and Kuwano H: Mutation and expression of the metastasis suppressor gene KAI1 in esophageal squamous cell carcinoma. Cancer 189: 955-962, 2000.

28. He B, Liu L, Cook GA, Grgurevich S, Jennings LK and Zhang XA: Tetraspanin CD82 attenuates cellular morphogenesis through down-regulating integrin $\alpha 6$-mediated cell adhesion. J Biol Chem 280: 3346-3354, 2005

29. Zijlstra A and Quigley JP: The DARC side of metastasis: Shining a light on KAI1-mediated metastasis suppression in the vascular tunnel. Cancer Cell 10: 177-178, 2006.

30. Odintsova E, Voortman J, Gilbert E and Berditchevski F: Tetraspanin CD82 regulates compartmentalisation and ligandinduced dimerization of EGFR. J Cell Sci 116: 4557-4566, 2003.

31. Cannon KS and Cresswell P: Quality control of transmembrane domain assembly in the tetraspanin CD82. EMBO J 20: 2443-2453, 2001.

32. Huang C I, Kohno N, Ogawa E, Adachi M, Taki T and Miyake M: Correlation of reduction in MRP-1/Cd9 and KAI1/ $\mathrm{Cd} 82$ expression with recurrences in breast cancer patients. Am J Path 153: 973-983, 1998.

33. Yang X, Wei LL, Tang C, Slack R, Mueller S and Lippman ME: Overexpression of KAI1 suppresses in vitro invasiveness and in vivo metastasis in breast cancer cells. Cancer Res 61: 5284-5288, 2001

34. Malik F, Sanders AJ, Douglas-Jones A, Mansel RE and Jiang WG: Kai-1 is aberrant expressed in human breast cancer and its link with cancer invasiveness. Br J Cancer (In press). 